\title{
Tarım topraklarındaki ağır metallerin kirlilik düzeylerinin belirlenmesi: Osmaniye örneği
}

\author{
Determination of heavy metal pollution levels in agricultural soils: the case of Osmaniye
}

\author{
Tuğba ŞiMŞEK ${ }^{1 \mathfrak{P}}$ (D), Nilgün KALKANCl ${ }^{1}$ (D) , Gökhan BÜYÜK ${ }^{2}$ (D) \\ ${ }^{1}$ Antepfıstığı Araştırma Enstitüsü Müdürlüğü, Gaziantep, Türkiye \\ ${ }^{2}$ Adıyaman Üniversitesi, Ziraat Fakültesi, Kahta-Adıyaman, Türkiye
}

MAKALE BILGISI / ARTICLE INFO

Makale tarihçesi / Article history:

DOI: $10.37908 /$ mkutbd.804262

Geliş tarihi /Received:05.10.2020

Kabul tarihi/Accepted:05.11.2020

\section{Keywords:}

Potential toxic heavy metals, food safety, heavy metal, pollution.

\footnotetext{
Corresponding author: Gökhan Büyük

$\bowtie$ : gbuyuk@adiyaman.edu.tr
}

\section{ÖZET / A B STR A C T}

\begin{abstract}
Aims: The aim of this study is to identify and thematically map potentially toxic heavy metal elements in soils in order to ensure sustainable use of intensively cultivated soils and to protect food safety.

Methods and Results: In this study, 165 soil samples (City center, 40; Kadirli, 83; Düziçi, 25; Hasanbeyli, 6; Toprakkale, 10 and Bahçe, 1) were taken from the areas representing the agricultural production lands in the province of Osmaniye and its districts. It was determined that the total $\mathrm{Mn}$, $\mathrm{Fe}, \mathrm{Ni}, \mathrm{Cd}$ and $\mathrm{Cr}$ in the toxic element results of these samples were above the specified limit values.

Conclusions: This may be due to the fact that the region is at the foot of the Taurus Mountains, the serpentine in the bedrock and/or some heavy metals such as $\mathrm{Cr}$ and $\mathrm{Ni}$ are high due to the mineralization of chromium. However, it can be said that $\mathrm{Cd}$ accumulation may be caused by phosphate fertilizers, since intensive fertilization is made. In the Fe analysis that can be taken in the soils taken from the study area, $92.7 \%$ of the iron content of the soils is less; $3.7 \%$ is medium; 3.6 of them were high.

Significance and Impact of the Study: The results obtained by carefully monitoring the passage of these metals to plants, animals and humans through the food chain through researches to be carried out, whether it is important for food safety or not, the data obtained as a result of analyzing suitable extractors and selecting the extractor with correlation calibration studies, whether it will be toxic or not with a different research. Needs to be clarified. This study is a case study and a study that reveals the possible heavy metal potential of the rocks in question. However, whether it will have an antagonistic effect on the transition to the plant by dissolving or the intake of other elements will be possible by investigating the extractable dose with various kileyt solvents.
\end{abstract}

Atıf / Citation: Şimşek T, Kalkancı N, Büyük G, (2021) Tarım Topraklarındaki Ağır Metallerin Kirlilik Düzeylerinin Belirlenmesi: Osmaniye Örneği. MKU. Tar. Bil. Derg. 26(1) : 106-116. DOI: 10.37908/mkutbd.804262

\section{GíRiş}

Hızlı sanayileşme ve tarımsal gübre, ilaç vb. ürünlerin son yıllarda tarımsal faaliyetlerde yaygın olarak uygulanmasıyla tarım arazileri ağır metal kirliliği ile karşı karşıya kalmaktadır (Zu ve ark., 2008; Zhang ve ark., 2009). Toprak kirliliğinin mevcut durumu ve dağılımı bizlere organik tarımın yapılabileceği alanların tespitini de mümkün kılacaktır. Bununla birlikte bölge topraklarında varsa toprak kirliliğinin belirlenmesi buralarda yapılacak bitkisel üretimin şeklini de belirleyecektir (Pandey ve Pandey, 2009).

Toprak, gıda üretiminin temeli olduğundan ve yetiştirilen ürünün bileşimini belirlediği için gıda güvenliğinde önemli rol oynamaktadır. Bununla birlikte, gıda zinciri boyunca zararlı elementlerin yayılması yoluyla insan 
sağlığı üzerindeki potansiyel etkileri ile tanımlanan toprak kaynaklarının kalitesi, yeterli ayrıntı ve güvenilirlik verilerinin bulunmaması nedeniyle yeterince çalışımamıştır (Tóth, ve ark., 2016). İnsan metabolizmasında olumsuz sağık etkilerine sahip ağır metaller kurşun $(\mathrm{Pb})$, kadmiyum $(\mathrm{Cd})$, cıva $(\mathrm{Hg})$, arsenik (As), bakır (Cu), nikel ( $\mathrm{Ni})$, çinko $(\mathrm{Zn})$ ve krom $(\mathrm{Cr})$ çevrede kalıcı olmaları ve ciddi sağlık sonuçları için belgelenmiş potansiyeli nedeniyle ciddi endişeler ortaya koymaktadır. Bu zehirli maddeler, çeşitli sindirim, deri teması, toprak-besin zinciri yoluyla beslenme, soluma ve ağızdan alım yoluyla insanlara ulaşabildiğini bildirmişlerdir (Khan ve ark., 2009; Lu ve ark., 2011).

Hızlı kentleşme ve nüfus artışı ile birlikte sanayileşmenin yarattığı çevre sorunları tarımsal alanları tehdit eder boyutlara ulaşmakta, bu sorunlar başta bilinçsiz gübre ve ilaç kullanımı gibi tarımın kendi iç dinamikleri ile oluşan sorunlara ilave olarak ve her geçen büyüyerek karşımıza çıkmaktadır. Tarım alanlarında kirliliğe neden olan ve gittikçe daha büyük boyutlarda tehlike oluşturan etmenlerin başında potansiyel toksik elementler ( $\mathrm{Cu}, \mathrm{Zn}$, $\mathrm{Ni}, \mathrm{Cd}, \mathrm{Cr}$, Pb ve Co) gelmektedir (Xu ve ark., 2018; Kırpık ve ark., 2017). Önemli bir kirletici grubu oluşturdukları bilinen bu elementler, bitkisel üretimde verimliliği olumsuz etkilemesi yanında, besin zincirine de girerek insan ve hayvan sağlığını da tehdit etmektedir.

Osmaniye farklı ana materyaller (bazalt, bazaltik tüf, marn, aluviyal, koluviyal, kireçtaşı, ofiyolit, serpantin) üzerinde oluşmuş 120 bin ha tarım alanı ile yoğun tarım yapılan bir ilimizdir. Günümüzde topraklarımızın sürdürülebilir olarak kullanılabilmesi ve gıda güvenliği için yapılan bu çalışmada, tarımsal toprakların potansiyel toksik element düzeylerinin belirlenmesi ve tematik olarak haritalandırılması amaçlanmıştır.

\section{MATERYAL ve YÖNTEM}

Bu çalışma, 2018-2019 yılları arasında Osmaniye ili ve ilçelerinde tarımsal üretim yapılan toprakları temsil eden alanlardan 0-20 cm derinlikten alınan 165 adet (Merkez, 40; Kadirli, 83; Düziçi, 25; Hasanbeyli, 6; Toprakkale, 10 ve Bahçe, 1 adet) toprak örneği kullanılmıştır.

\section{Toprak örneklerinin alınması}

Toprak örnek sayısını tespit etmek için, 1/25000 ölçekteki toprak haritalarından; sulu tarım, kuru tarım, bağ, bahçe, çay, zeytin, turunçgil vb tarım yapılan alanlar dikkate alınarak çalışma alanı belirlenmiştir. Türkiye haritası üzerinde $2.5 \times 2.5 \mathrm{~km}$ 'lik gridler oluşturulmuş ve tarım alanlarına düşen noktalar seçilerek, alınacak örnek sayısı tespit edilmiştir. Bu gridleme sistemi içerisinde topografya, ana toprak grupları, arazi kullanım kabiliyet sınıfları, nehir, dağ, göl, yerleşim alanları, tarım dışı kullanım alanları sınırlamaları vb kullanım alanlarına gelen noktalar iptal edilmiştir. Yer koordinatları $(2.5 \times 2.5)$ km grid sistemine göre 1/100.000 ölçekli arazi paftaları işaretlenmiştir. GPS ve çalışma paftası yardımıyla örneklemeler yapılırken GPS ile koordinatlar okunmuştur.

\section{Toprak örneklerinin analiz yöntemleri}

Laboratuvara getirilen toprak örnekleri, taş ve bitki parçacıkları ayıklanmış ve gölgede kurumaya bırakılmıştır. Kuruyan topraklar tokmaklarla dövülerek 2 mm'lik çelik elekten geçirilmiş ve aşağıda belirtilen analizler yapılmıştır.

\section{Alınabilir demir, bakır, çinko ve mangan analizleri}

Bitkiye yarayışlı mikro element ( $\mathrm{Fe}, \mathrm{Cu}, \mathrm{Zn}, \mathrm{Mn}$ ) miktarları, Lindsay ve Norvell (1978) tarafından bildirildiği şekilde, DTPA ile ekstrakte edildikten sonra, elde edilen süzüklerdeki $\mathrm{Fe}, \mathrm{Cu}, \mathrm{Zn}$ ve $\mathrm{Mn}$ miktarları ICP'de (Varian 710 Model) belirlenmiştir.

\section{Alınabilir kadmiyum, krom, nikel ve kobalt analizleri} Toprakların alınabilir $\mathrm{Cd}, \mathrm{Cr}$, Ni ve Co miktarları DTPA ile hazırlanan ekstrakte edildikten sonra ICP'de (Varian 710 Model) belirlenmiştir (Lindsay ve Norvell, 1978).

Toplam Potansiyel Toksik Element Analizleri $\left(\mathrm{mg} \mathrm{kg}^{-1}\right)$ : Toplam ağır metal ( $\mathrm{Cu}, \mathrm{Cd}, \mathrm{Cr}, \mathrm{Pb}, \mathrm{Co}, \mathrm{Fe}, \mathrm{Mn}, \mathrm{Ni}$ ve $\mathrm{Zn})$ içeriklerini belirlemek için $2 \mathrm{~mm}$ 'lik elekten geçirilmiş topraktan $25 \mathrm{~g}$ alınmıştır. Üzerine $50 \mathrm{ml}$ kral suyu $\left(\mathrm{HNO}_{3}: \mathrm{HCl}\right.$ karışımı, 1:3 oranında) ile mikro dalga aletinde yakılmıştır. Ekstraktlar varian ICP-710'de okunarak belirlenmiştir.

\section{BULGULAR VE TARTIŞMA}

\section{Toprak örneklerinin toplam $\mathrm{Fe}, \mathrm{Cu}, \mathrm{Zn}$ ve $\mathrm{Mn}$} içeriklerinin değerlendirilmesi

Topraklarda bulunan ağır metallerin değerlendirilmesi 2010 yılında Çevre ve Orman Bakanlığı tarafından yayımlanan Toprak Kirliliğinin Kontrolü ve Noktasal Kaynaklı Kirlenmiş Sahalara Dair Yönetmelik tarafından toprakta müsaade edilen ağır metal sınır değerlerine (Çizelge 1) göre değerlendirilmiştir (Anonim, 2010). 
Çizelge 1. Araştırma alanına ait topraklardaki ağır metal konsantrasyonu sınır değerleri Table 1. Heavy metal concentration limit values in soils belonging to the research area

\begin{tabular}{ccc} 
Ağır & $\begin{array}{c}\mathrm{pH} 5-6 \\
\text { Metal }\end{array}$ & $\begin{array}{c}\mathrm{pH}>6 \\
\text { (mg/kg kuru toprak) }\end{array}$ \\
$\mathrm{Pb}$ & 50 & 300 \\
$\mathrm{Cd}$ & 1 & 3 \\
$\mathrm{Ni}$ & 30 & 75 \\
$\mathrm{Cr}$ & 100 & 100 \\
$\mathrm{Co}$ & 80 & 80 \\
$\mathrm{Cu}$ & 50 & 140 \\
$\mathrm{Zn}$ & 150 & 300 \\
\hline
\end{tabular}

Toplam demir, toprakta bulunan dördüncü en bol elementtir, ancak büyük ölçüde bitkiler tarafından alınamayacak formlarda bulunur. Araştırma alanı topraklarının toplam Fe içerikleri Çizelge $2^{\prime}$ de verilmiş olup toplam Fe miktarı 3096-45596 $\mathrm{mg} \mathrm{kg}^{-1}$ arasında değişmektedir (Çizelge 2). Ortalama olarak $17096 \mathrm{mg} \mathrm{kg}^{-}$ ${ }^{1}$ dir. Standart sapması $7837 \mathrm{mg} \mathrm{kg}^{-1}$ olarak hesaplanmıştır. Çizelge $1^{\prime}$ de belirtilen sınır değerden oldukça yüksek düzeyde ölçülmüştür. Tipik olarak

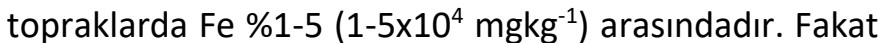
bu oranın büyük bölümü bitkiler tarafından kullanılamamaktadır. Bölge topraklarında yerfıstığı ve soya gibi bazı bitkilerde gözle görülebilir Fe eksikliği bulunmaktadır (Gönül ve ark., 2019). Araştırma alanı toprakları volkanik kaya olan bazalt üzerinde olduğundan toprakların toplam $\mathrm{Fe}$ içeriğinin yüksek olmasını açıklamaktadır (Lavkor ve Çelik, 2006). Çalışma alanından alınan topraklarda alınabilir demir içerikleri Lindsay ve Norwell 1978'e göre, \%92,7'si az (<0.2 mg kg$\left.{ }^{1}\right), \% 3,7^{\prime}$ sı orta $\left(0.2-2 \mathrm{mg} \mathrm{kg}^{-1}\right), 3,6^{\prime}$ sı yüksek $\left(>2 \mathrm{mg} \mathrm{kg}^{-1}\right)$ bulunmuştur.

Çizelge 2. Araştırma alanı topraklarının toplam demir dağılımı (mg kg-1) (TAGEM,2018)

Table 2. Total iron distribution of the research area soils $\left(\mathrm{mg} \mathrm{kg}^{-1}\right)$

\begin{tabular}{lcccc}
\hline Element & $\mathrm{Fe}\left(\mathrm{mg} \mathrm{kg}^{-1}\right)$ & Sınıfı & Örnek sayısı & Dă̈ılımı (\%) \\
\hline \multirow{4}{*}{ Demir } & $0-10000$ & Yok veya hafif & 32 & 19.4 \\
& $10001-20000$ & Hafiften ortaya & 74 & 44.8 \\
& $20001-30000$ & Ortadan yükseğe & 47 & 28.5 \\
& $30001-40000$ & Yüksekten çok yükseğe & 11 & 6.7 \\
& $40001-$ & Aşırı & 1 & 0.6 \\
\hline
\end{tabular}

Araştırma alanı topraklarının toplam $\mathrm{Mn}$ değerleri 7-925 $\mathrm{mg} \mathrm{kg}^{-1}$ arasında ölçülmüştür (Çizelge 3). Ortalama olarak $127 \mathrm{mg} \mathrm{kg}^{-1}$, standart sapması 143 olarak belirlenmiştir. Toprakların \%42'si sınır değer olan $70 \mathrm{mg} \mathrm{kg}^{-1}$ in üzerinde ölçülmüştür. Mangan elementi bitkilerde klorofil sentezi ve azot absorspsiyonunda önemli rol oynamakta ve $\mathrm{Fe}$ eksikliğine yol açmaktadır (Bolat ve Kara, 2017). Krom $(\mathrm{Cr})$, kurşun $(\mathrm{Pb})$ ve manganez $(\mathrm{Mn})$ gibi yoğunluğu 5 $\mathrm{g} / \mathrm{cm}^{3}$ ten fazla olan ağır metaller, Dünya'nın kabuğunun doğal bileşenleri olduğundan bu bölgede bulunan maden yataklarından dolayı total $\mathrm{Mn}$ içeriği yüksek görülebilir. (>6.1 $\mathrm{mg} \mathrm{kg}^{-1}$ ) olarak belirlenmiştir.
$\mathrm{Bu}$ elementler insan vücuduna yiyecek, içme suyu ve/veya hava ile girebilirler ve büyük miktarlarda toksik hale gelebilirler (Buczyńska and Tarkowski 2005). Bu nedenle bölgede yetiştirilen tarımsal ürünlerde topraktan bitkiye mangan geçişi konusunda inceleme yapılmalıdır. Çalışma alanına ait toprakların toplam Fe ve Mn dağılımını gösteren harita Şekil 1'de verilmiştir. Çalışma alanı topraklarının alınabilir $\mathrm{Mn}$ analiz sonuçlarına göre; toprakların\%12,1'inde (3,1-6,0 mg kg $\left.{ }^{1}\right)$ alınabilir Mn içeriği yüksek, \%87.9' unda ise çok yüksek bulunmuştur. 
Çizelge 3. Araştırma alanı topraklarının toplam mangan dağılımı $\left(\mathrm{mg} \mathrm{kg}^{-1}\right)$ (TAGEM, 2018)

Table 3. Total manganese distribution of the research area soils $\left(\mathrm{mg} \mathrm{kg}^{-1}\right)$

\begin{tabular}{lcccc}
\hline Element & $\mathrm{Mn}\left(\mathrm{mg} \mathrm{kg}^{-1}\right)$ & Sınıfı & Örnek Sayısı & Dağılımı (\%) \\
\hline \multirow{3}{*}{ Mangan } & $0-50$ & Yok veya hafif & 44 & 26.7 \\
& $51-100$ & Hafiften ortaya & 54 & 32.7 \\
& $101-150$ & Ortadan yükseğe & 26 & 15.7 \\
& $151-200$ & Yüksekten çok yükseğe & 15 & 9.2 \\
& $201-$ & Aşırı & 26 & 15.7 \\
\hline
\end{tabular}

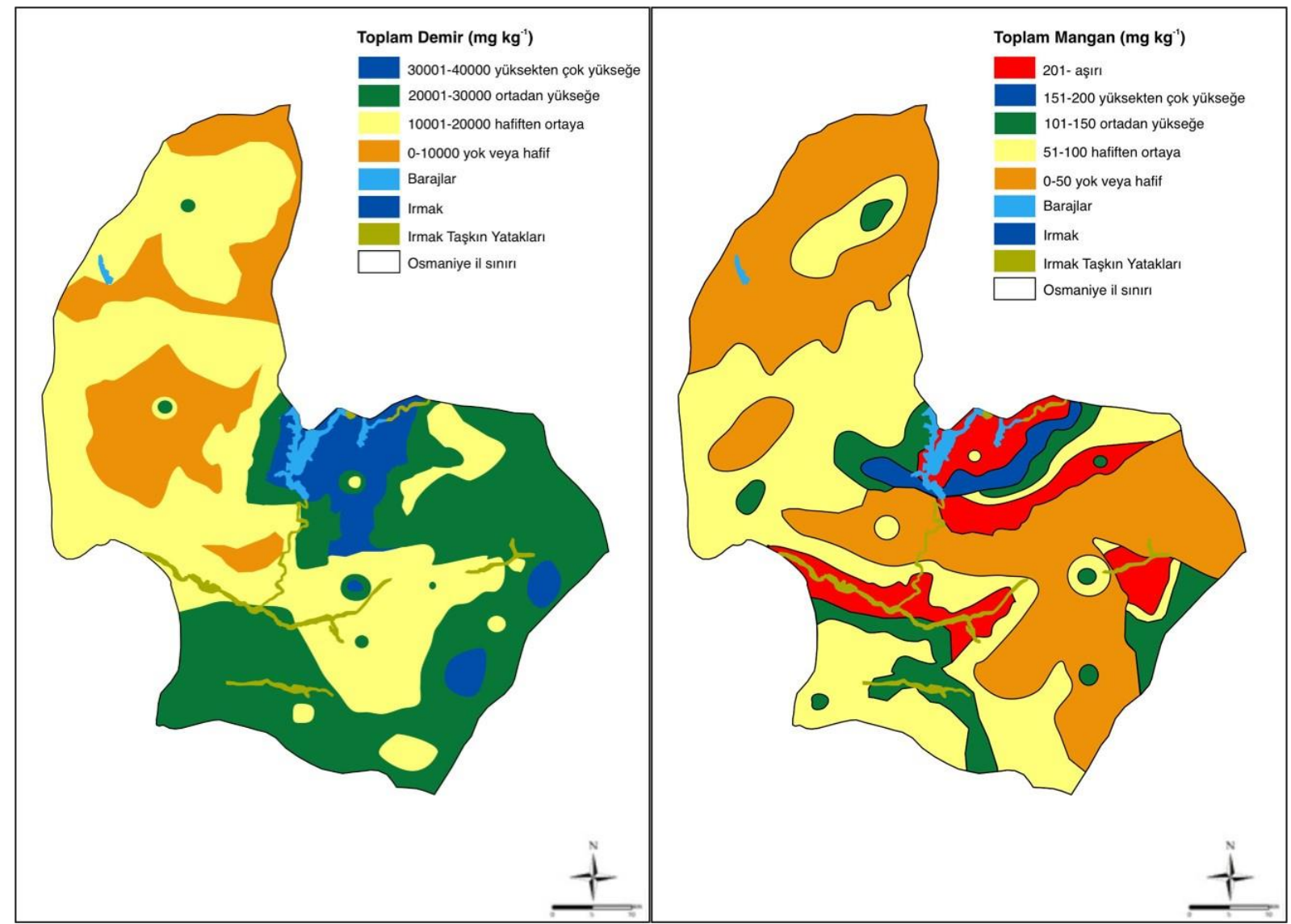

Şekil 1. Araştırma alanı topraklarının toplam demir ve mangan dağııımını gösteren harita Figure 1. Map showing the total iron and manganese distribution of the research area soils

Araştırma alanı topraklarında toplam bakır düzeyleri belirtilen sınır değer olan $140 \mathrm{mgkg}^{-1}$ in altında belirlenmiştir. Bölge topraklarında toplam bakır birikimi bulunmamaktadır (Çizelge 4). Topraklarda toplam $\mathrm{Cu}$ içeriği 6-73 $\mathrm{mg} \mathrm{kg}^{-1}$ arasında değişmiş ortalama $19 \mathrm{mg} \mathrm{kg}^{-}$ 1 olarak ölçülmüştür. Standart sapma 8 olarak belirlenmiştir. Buna göre Osmaniye ili topraklarının alınabilir $\mathrm{Cu}$ içerikleri \%2,4'ü az $\left(<0.2 \mathrm{mg} \mathrm{kg}^{-1}\right)$; \%93.9'u orta $\left(0.2-2 \mathrm{mg} \mathrm{kg}^{-1}\right), \% 3,7^{\prime}$ si yüksek $\left(>2 \mathrm{mg} \mathrm{kg}^{-1}\right.$ ) bulunmuştur. Ayrıca Osmaniye topraklarının toplam $\mathrm{Cu}$ içeriklerini gösteren harita Şekil 2'de verilmiştir. 
Çizelge 4. Araştırma alanı topraklarının toplam bakır dağılımı $\left(\mathrm{mg} \mathrm{kg}^{-1}\right)($ TAGEM,2018)

Table 4. Total copper distribution of the research area soils $\left(\mathrm{mg} \mathrm{kg}^{-1}\right)$

\begin{tabular}{lcccc}
\hline Element & $\mathrm{Cu}\left(\mathrm{mg} \mathrm{kg}^{-1}\right)$ & Sınıfı & Örnek Sayısı & Dağılımı (\%) \\
\hline \multirow{3}{*}{ Bakır } & $0-10$ & Yok veya hafif & 11 & 6,7 \\
& $10,1-20$ & Hafiften ortaya & 99 & 60,0 \\
& $20,1-50$ & Ortadan yükseğe & 53 & 32 \\
& $50,1-150$ & Yüksekten çok yükseğe & 2 & 1,3 \\
\hline
\end{tabular}

Toprakların toplam çinko dağılımı 19-105 mg kg-1 arasında değişmektedir. Ortalama olarak $52 \mathrm{mg} \mathrm{kg}^{-1}$, standart sapması 15 olarak belirlenmiştir. Sınır değerler (300 mg kg ${ }^{-1}$ ) ile karşılaştırıldığında topraklarda $\mathrm{Zn}$ birikimi belirlenmemiştir (Çizelge 5). Buna göre
Osmaniye ili topraklarının alınabilir çinko içerikleri \%90,9'u çok az (0-1,5 $\left.\mathrm{mg} \mathrm{kg}^{-1}\right), \% 5,45^{\prime} \mathrm{i}$ az (1.6-3 $\left.\mathrm{mg} \mathrm{kg}^{-1}\right)$, $\% 3,65^{\prime} \mathrm{i}$ orta $\left(3.1-20 \mathrm{mg} \mathrm{kg}^{-1}\right)$ bulunmuştur. Ayrıca Osmaniye topraklarının toplam çinko kapsamına göre içeriklerini gösteren harita Şekil 2'de verilmiştir.

Çizelge 5. Araştırma alanı topraklarının toplam çinko dağılımı $\left(\mathrm{mg} \mathrm{kg}^{-1}\right)(\mathrm{TAGEM}, 2018)$

Table 5. Total zinc distribution of the research area soils $\left(\mathrm{mg} \mathrm{kg}^{-1}\right)$

\begin{tabular}{lcccc}
\hline Element & $\mathrm{Zn}\left(\mathrm{mg} \mathrm{kg}^{-1}\right)$ & Sınıfı & Örnek Sayısı & Dağılımı (\%) \\
\multirow{2}{*}{ Çinko } & $0-50$ & Yok veya hafif & 75 & 45,5 \\
& $50,1-100$ & Hafiften ortaya & 88 & 53,3 \\
& $101-150$ & Ortadan yükseğe & 2 & 1,2
\end{tabular}

Toprak örneklerinin toplam $\mathrm{Ni}, \mathrm{Pb}, \mathrm{Cd}$, Co ve $\mathrm{Cr}$ içeriklerinin değerlendirilmesi

Topraklarda toplam Ni sınır değeri olarak $75 \mathrm{mg} \mathrm{kg}^{-1}$ olarak belirlenmiştir. Araştırma alanı toprakları 16-989 $\mathrm{mg} \mathrm{kg}^{-1}$ arasında değişmekle birlikte ortalama $233 \mathrm{mg} \mathrm{kg}^{-}$ 1 olarak ölçülmüştür. Standart sapması 267 olarak hesaplanmıştır. Toprakların \%58'inde toplam $\mathrm{Ni}$ sınır değerin üzerine ölçülmüştür (Çizelge 6). Fazla nikel, başta demir olmak üzere diğer temel besin maddelerinin alımını engelleyebilir (Lešková ve ark., 2017). Bu durum bölgedeki Fe eksikliğinin bir nedeni olabilir. Bu durum tarımsal üretim için tehlike oluşturmayabilir. Ama $\mathrm{Cr}$ ve
Ni'in tarımsal ekosistemlere ve özellikle mineral ayrışma sırasında doğal su sistemlerine salınması meydana gelebilir (Oze et al. 2008). Araştırma alanı topraklarının toplam $\mathrm{Ni}$ dağılımını gösteren harita Şekil 3'de verilmiştir. Bitki beslenmesi için eser miktarda nikele ihtiyaç duyulmasına rağmen, aşırı konsantrasyonlar bitkilerin vejetatif büyümesi için ciddi sorunlar oluşturabilir ve ekosistemdeki biyokütle üretimini engelleyebilir (Khan ve Kahn, 2010). Gıda zinciri yoluyla insan ve hayvan sağlığına zararlı etkileri olabilir (Nakonieczny, 2007). Toprakların alınabilir Ni konsantrasyonu 0,02-29,8 $\mathrm{mg} \mathrm{kg}^{-1}$ arasında ölçülmüştür. 


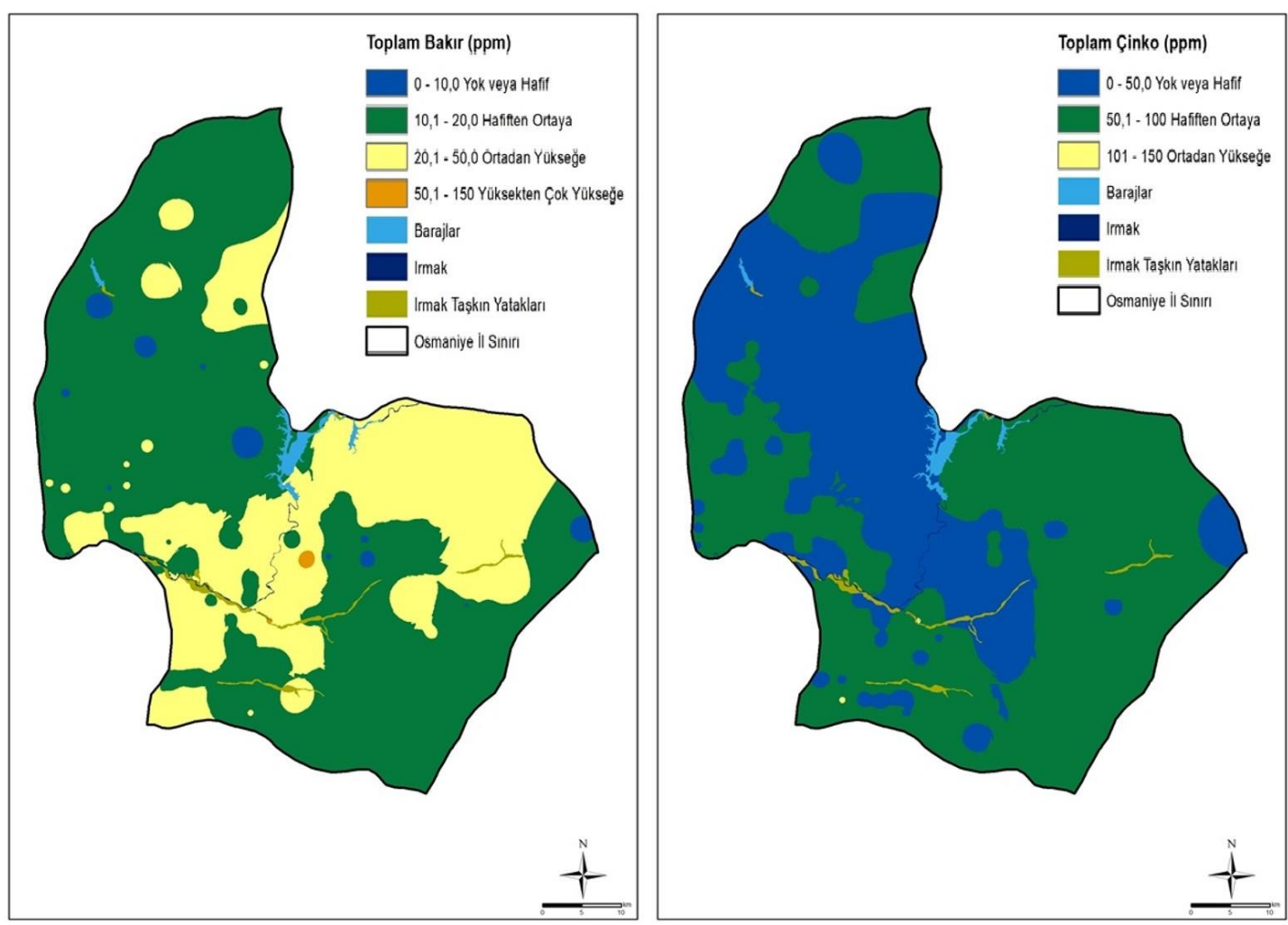

Şekil 2. Araştırma alanı topraklarının toplam çinko ve bakır dağılımını gösteren harita Figure 2. Map showing the total zinc and copper distribution of the research area soils

Çizelge 6. Araştırma alanı topraklarının toplam nikel dağılımı $\left(\mathrm{mg} \mathrm{kg}^{-1}\right)(T A G E M, 2018)$

Table 6. Total nickel distribution of the research area soils $\left(\mathrm{mg} \mathrm{kg}^{-1}\right)$

\begin{tabular}{lcccc}
\hline Element & $\mathrm{Ni}\left(\mathrm{mg} \mathrm{kg}^{-1}\right)$ & Sınıfı & Örnek Sayısı & Dağılımı (\%) \\
\hline \multirow{3}{*}{ Nikel } & $0-30$ & Yok veya hafif & 9 & 5,5 \\
& $30,1-75,0$ & Hafiften ortaya & 60 & 36,4 \\
& $75,1-125$ & Ortadan yükseğe & 23 & 13,9 \\
& $126-200$ & Yüksekten çok yükseğe & 18 & 10,9 \\
& $>200$ & Aşırı yüksek & 55 & 33,3 \\
\hline
\end{tabular}

Ülkemizde topraklarda toplam Cd'un sınır değeri 3 mg kg1 olarak kabul edilmektedir. Topraklarda toplam $\mathrm{Cd}$ içeriği 1-9 $\mathrm{mg} \mathrm{kg}^{-1}$ arasında değişirken ortalama $3 \mathrm{mgkg}^{-1}$ olarak belirlenmiştir (Çizelge 7). Standart sapması 2'dir. Toprakların \%48'inde toplam Cd birikimi belirlenmiştir. Kadmiyum, pil üretiminde kullanılan zehirli bir elementtir ve sigara dumanında, bazı boyalarda, toprak çinko katkı maddelerinde, bazı gübrelerde (özellikle fosfor içerenlerde) ve bazı gübrelerde bulunur. Madencilik gibi endüstriyel faaliyetler toprak kadmiyum seviyelerini artırabilir. Bu bölgede madenciliğin yoğun bir şekilde yapıldığı ve intensif tarımdan dolayı yoğun gübre kullanılmaktadır. Cd birikiminin neden olduğu daha detaylı araştırılmalıdır (Salmanzadeh ve ark., 2016).
Araştırma alanı toprakların Cd dağılımını gösteren harita Şekil 3'de verilmiştir. Ayrıca topraklarda Cd yüksekliğinde, bitkiler tarafından alınan $\mathrm{Cd}$, yenilebilir kısımlarda birikerek, gıda ürünlerinin veriminde ve kalitesinde önemli bir düşüşe yol açabilmektedir (Tang ve ark., 2019). Toprakların alınabilir çinko içerikleri incelendiğinde toprakların; \%90,9'u çok az; \%5,45'i az; $\% 3,65$ 'inde çinko miktarı orta bulunmuştur. Topraklarda Zn konsantrasyonu az olması bitkiler tarafından Cd alımı da arttırmaktadır (Rascio ve Navari-Izzo, 2011). Bitkilerde birikmesinin diğer nedeninin $\mathrm{pH}$ ve bitki genotipleri olduğu bildirilmiştir (Li ve ark., 2005). Toprakların alınabilir Cd konsantrasyonları 1,3-127,3 ug $\mathrm{kg}^{-1}$ aralığında ölçülmüştür. 
Çizelge 7. Araştırma alanı topraklarının toplam kadmiyum dağılımı $\left(\mathrm{mg} \mathrm{kg}^{-1}\right)(\mathrm{TAGEM}, 2018)$ Table 7. Total cadminyum distribution of the research area soils $\left(\mathrm{mg} \mathrm{kg}^{-1}\right)$

\begin{tabular}{lcccc}
\hline Element & $\mathrm{Cd}\left(\mathrm{mg} \mathrm{kg}^{-1}\right)$ & Sınıfı & Örnek Sayısı & Dağılımı (\%) \\
\hline \multirow{2}{*}{ Kadmiyum } & $0-1,0$ & Yok veya hafif & 4 & 2,4 \\
& $1,01-3,0$ & Hafiften ortaya & 82 & 49,7 \\
& $3,01-5,0$ & Ortadan yükseğe & 51 & 30,9 \\
& $5,01-10,0$ & Yüksekten çok yükseğe & 28 & 17,0 \\
\hline
\end{tabular}
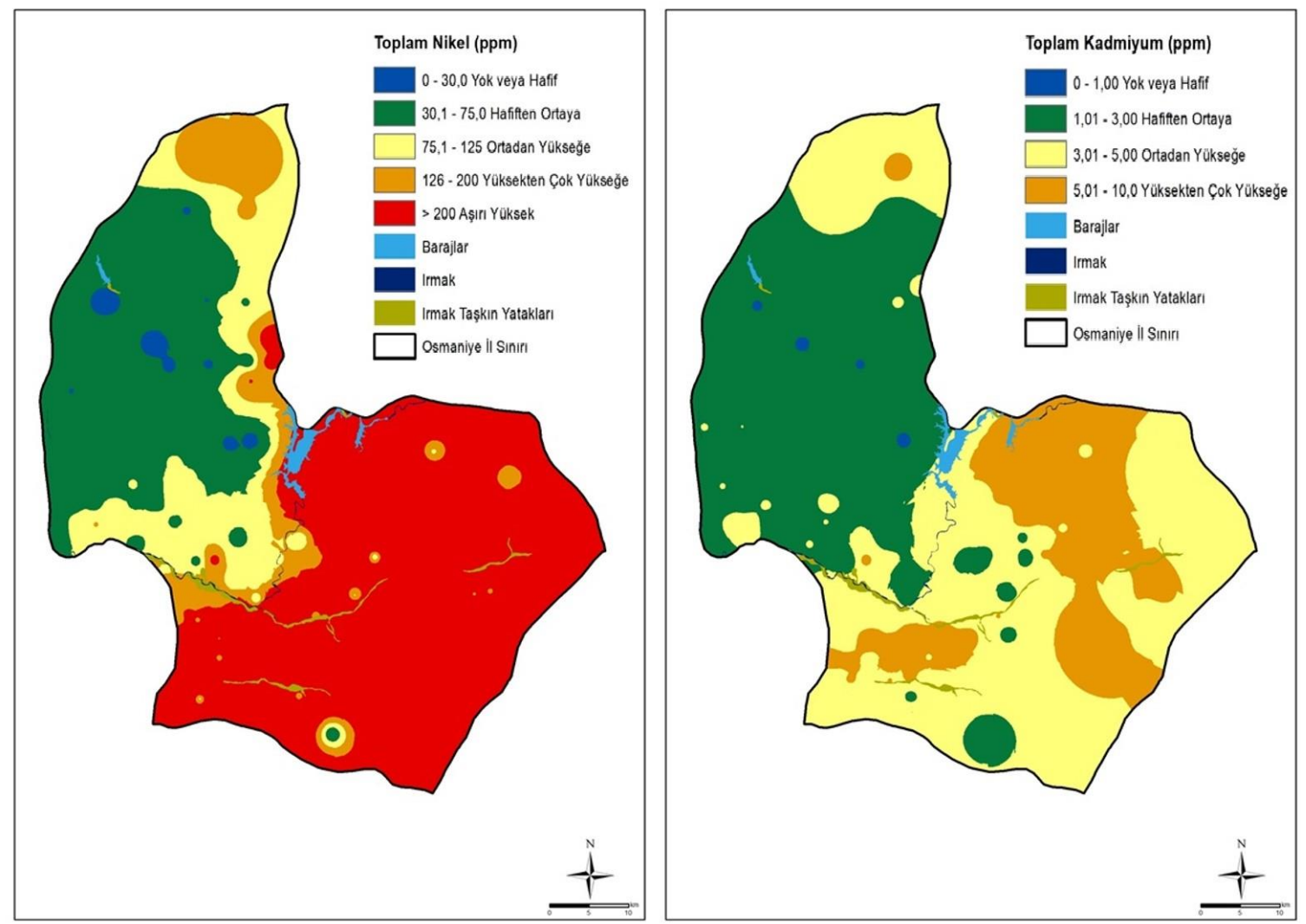

Şekil 3. Araştırma alanı topraklarının toplam nikel ve kadmiyum dağılımını gösteren harita Figure 3. Map showing the total nickel and cadminyum distribution of the research area soils

Türkiye' de topraklarda krom için sınır değeri $100 \mathrm{mg} \mathrm{kg}^{-1}$ olarak kabul edilmektedir. Araştırma alanı topraklarının toplam krom içeriği 7-530 mg kg-1 arasında değişirken ortalama $103 \mathrm{mg} \mathrm{kg}^{-1}$ olarak belirlenmiştir. Standart sapması 124'dür. Toprakların \%28,4'ü krom içeriği bakımından sınır değerin üzerinde ölçülmüştür (Çizelge 8). Krom, kayalarda ve toprakta doğal olarak oluşan bir elementtir (Seven ve ark., 2018). Doğal toprak tipik olarak her kg toprak için 10 ila 50 mg krom içerir. Bunun nedeni bölgedeki toprakların ana materyalinden ve/veya jeolojisinden kaynaklanmaktadır. Topraklarda bulunan total kromun yarayışlı hale geçerek bitki köklerine geçişi ve bitkilerdeki düzeyi takip edilmelidir. Toprakta yüksek krom seviyeleri tespit edilmesi durumunda, iyileştirme için bazı seçenekler bulunmaktadır. Krom toksisitesinden kaynaklanan besin eksiklikleri, mikorizalar ile iyileştirilebilir (Kullu ve ark., 2020). Araştırma alanı topraklarının toplam $\mathrm{Cr}$ dağııımını gösteren harita Şekil 4'de verilmiştir. Bu topraklarda yetiştirilen bitkiler, yüksek konsantrasyonda ağır metal biriktirebilir ve tüketildiğinde insan sağlığı için ciddi risk oluşturmaktadır (Naser ve ark., 2012). Araştırma alanı toprak örneklerinin alınabilir $\mathrm{Cr}$ içerikleri 0,04-65,1 ug kg-1arasında olduğu belirlenmiştir. 
Çizelge 8. Araştırma alanı topraklarının toplam krom dağılımı $\left(\mathrm{mg} \mathrm{kg}^{-1}\right)(T A G E M, 2018)$

Table 8. Total chrome distribution of the research area soils $\left(\mathrm{mg} \mathrm{kg}^{-1}\right)$

\begin{tabular}{lcccc}
\hline Element & $\mathrm{Cr}\left(\mathrm{mg} \mathrm{kg}^{-1}\right)$ & Sınıfı & Örnek Sayısı & Dağılımı (\%) \\
\hline \multirow{4}{*}{ Krom } & $0-50,0$ & Yok veya hafif & 93 & 56,4 \\
& $50,1-100$ & Hafiften ortaya & 26 & 15,8 \\
& $101-150$ & Ortadan yükseğe & 7 & 4,2 \\
& $151-300$ & Yüksekten çok yükseğe & 21 & 12,7 \\
& $>300$ & Aşırı yüksek & 18 & 10,9 \\
\hline
\end{tabular}

Araştırma alanı topraklarında toplam kobalt içeriği 0$1.09 \mathrm{mg} \mathrm{kg}^{-1}$ arasında değişirken ortalama $0.16 \mathrm{mg} \mathrm{kg}^{-1}$ olarak belirlenmiştir. Standart sapması 0,20 olarak hesaplanmıştır. Topraklarda toplam kobalt sınır değeri
$80 \mathrm{mg} \mathrm{kg}^{-1 \prime}$ dir. Kobalt birikimi ile ilgili problem olmadığı belirlenmiştir (Çizelge 9). Bitkilerce alınabilir kobalt elementi; Osmaniye ilinin topraklarında 0,22-1038,3 ug $\mathrm{kg}^{-1}$ arasında ölçülmüştür.

Çizelge 9. Araştırma alanı topraklarının toplam kobalt dağıımı $\left(\mathrm{mg} \mathrm{kg}^{-1}\right)(T A G E M, 2018)$

Table 9. Total cobalt distribution of the research area soils $\left(\mathrm{mg} \mathrm{kg}^{-1}\right)$

\begin{tabular}{llll}
\hline Element & Co $\left(\mathrm{mg} \mathrm{kg}^{-1}\right)$ & Sınıfı & Örnek Sayısı
\end{tabular}

Kobalt

$0-5,0$

Yok veya hafif

165

100

Toprakların toplam kurşun içeriği $0.02-13.02 \mathrm{mg} \mathrm{kg}^{-1}$ arasında değişirken ortalaması $2.73 \mathrm{mg} \mathrm{kg}^{-1}$ olarak belirlenmiştir. Standart sapması $3.14^{\prime}$ dür. Kabul edilen sınır değerin $300 \mathrm{mgkg}^{-1}$ olduğu düşünüldüğünde topraklarda kurşun elementi ile ilgili bir sorun olmadığı görülmektedir (Çizelge 10). Araştırma alanı topraklarının toplam $\mathrm{Pb}$ dağılımını gösteren harita Şekil 4'de verilmiştir.

Çizelge 10. Araştırma alanı topraklarının toplam kurşun dağılımı $\left(\mathrm{mg} \mathrm{kg}^{-1}\right)(\mathrm{TAGEM}, 2018)$

Table 10. Total lead distribution of the research area soils $\left(\mathrm{mg} \mathrm{kg}^{-1}\right)$

\begin{tabular}{lcccc}
\hline Element & $\mathrm{Pb}\left(\mathrm{mg} \mathrm{kg}^{-1}\right)$ & Sınıfı & Örnek Sayısı & Dağılımı (\%) \\
\hline Kurşun & $0-300$ & Yok veya Hafif & 165 & 100 \\
\hline
\end{tabular}
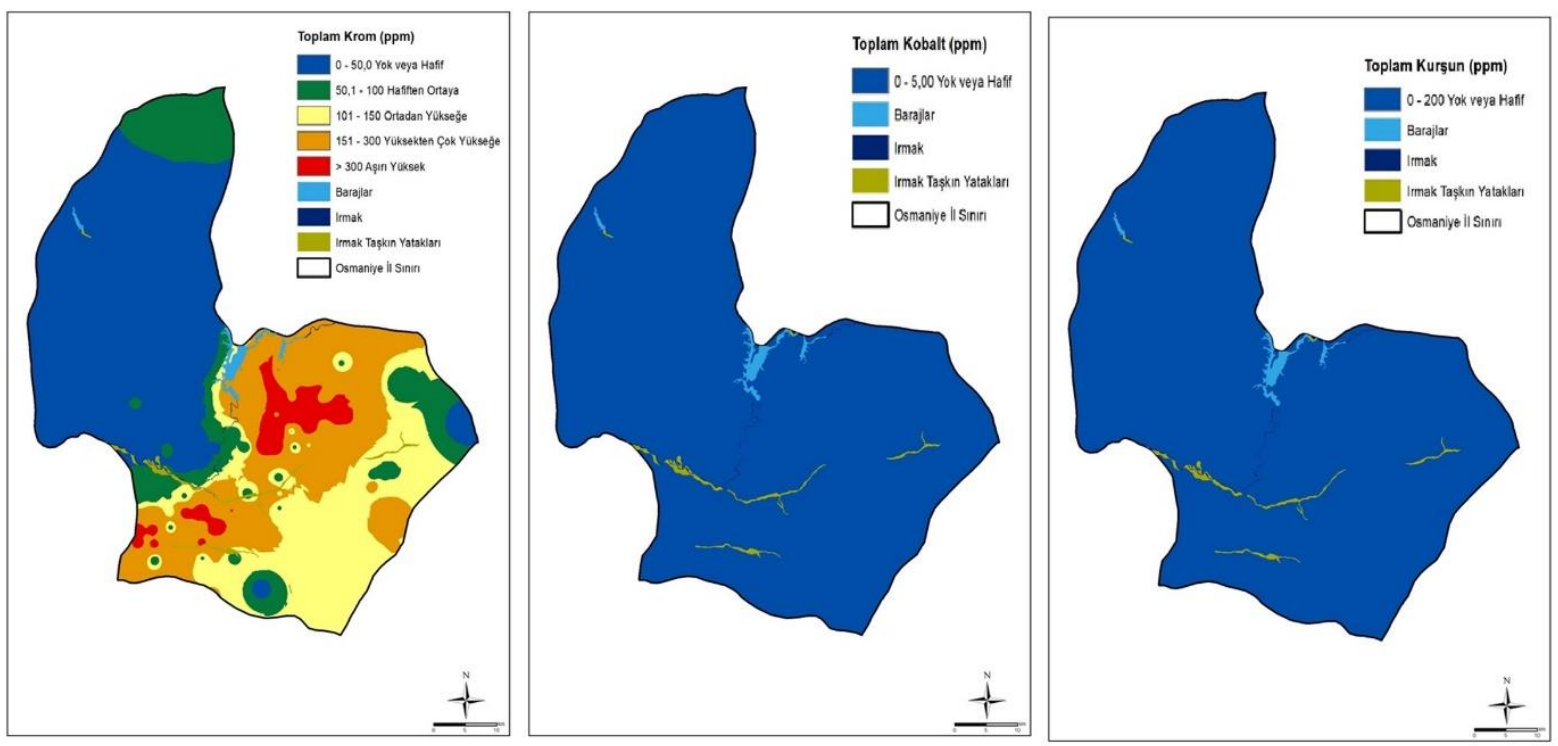

Şekil 4. Araştırma alanı topraklarının toplam krom, kobalt ve kurşun dağııımını gösteren harita Figure4. Map showing the total chrome, cobalt and lead distribution of the research area soils 


\section{SONUÇ ve ÖNERILER}

Toprak ana materyalinden kaynaklanan ya da kirlilik yoluyla açığa çıkan yüksek konsantrasyonlu bazı ağır metaller, bitkileri ve bunlarla beslenen hayvanları olumsuz yönde etkileyebilmektedir. Bu ağır metallerin topraktaki davranışları toprakların fiziksel, kimyasal yapısı vb süreçlerle değişmekle birlikte bitkilerin bu elementleri bünyelerine almaları ile de yakından ilgilidir. Araştırma alanı olanı Osmaniye ili tarımsal alanları yoğun tarım yapılan yılda 2-3 defa ürün alınabilen tarımsal alanlardır. Bu alanları temsil eden noktalardan alınan toprak örneklerinde yapılan ölçümlerde; toplam $\mathrm{Mn}$ içeriğinin (\%42), toplam $\mathrm{Fe}(\% 100)$, toplam $\mathrm{Ni}(\% 58)$, toplam $\mathrm{Cd}(\% 48)$ ve toplam $\mathrm{Cr} \quad(\% 28,4)$ konsantrasyonunun Türkiye'de Toprak Kirliliğinin Kontrolü Yönetmeliğine göre $\mathrm{pH}^{\prime} \mathrm{sı}$ 6'nın üzerinde olan topraklarda kabul edilen toplam sınır değerlerin üzerinde olduğu tespit edilmiştir. Her ne kadar bazı ağır metallerin toprakta ölçülen toplam değerleri yüksek bulunmuşsa da yapılacak araştırmalar ile toprakta bulunan toplam konsantrasyondan bitkiye geçişin olup olmadığı varsa geçişin ne düzeyde olduğu yapılacak araştırmalarla belirlenmelidir. Bölge topraklarında kirliliğe sebep olan parametrelerin genellikle çevresel faktörlere bağlı olarak oluştuğu, Cr ve Ni element artışında ise kısmen bölgedeki jeolojik yapının da katkısı olduğu düşülmektedir. $\mathrm{Cr}$ elementinin Toros Dağlarının yakınlarında bulunan krom cevherleşmesinden kaynaklanabileceği gibi özellikle serpantin gibi ana materyale sahip olan topraklarda $\mathrm{Cr}$ ve $\mathrm{Ni}$ değerleri yüksek çıkabilmektedir. Ama yoğun olarak fosforlu gübreleme yapıldığından Cd birikiminin fosfatlı gübreden kaynaklanabileceği de söylenebilir. Bu alanlarda Fe eksikliğinin gözle görülebilir olması ve bu eksikliğin bu ağır metallerin fazlalığından kaynaklanabileceği de kaynaklarda belirtilmiştir. Bu nedenle bu metallerin yapılacak araştırmalarla bitkilere, hayvanlara ve insanlara geçişi dikkatlice izlenmesi gıda güvenliği açısından önem taşımaktadır.

\section{ÖZET}

Amaç: Bu çalışmanın amacı, yoğun tarım yapılan toprakların sürdürülebilir olarak kullanılabilmesi ve gıda güvenliğini korumak için bu topraklarda potansiyel toksik ağır metal elementlerin belirlenmesi ve tematik olarak haritalandırılmasıdır.

Yöntem ve Bulgular: Osmaniye ili ve ilçelerinde tarımsal üretim yapılan toprakları temsil eden alanlardan $0-20 \mathrm{~cm}$ derinlikten alınan 165 adet (Merkez, 40; Kadirli, 83; Düziçi, 25; Hasanbeyli, 6; Toprakkale, 10 ve Bahçe, 1 adet) toprak örneği alınmıştır. Bu örneklerin potansiyel toksik element analizdeki sonucu toplam $\mathrm{Mn}, \mathrm{Fe}, \mathrm{Ni}, \mathrm{Cd}$ ve $\mathrm{Cr}$ konsantrasyon değerleri belirtilen sınır değerlerin üzerinde olduğu belirlenmiştir.

Genel Yorum: Bölge Toros dağlarının eteğinde olması ana kayada serpantin olması ve/veya kromun cevherleşmesinden dolayı $\mathrm{Cr}$ ve $\mathrm{Ni}$ gibi bazı ağır metallerin yüksek olması bu nedenlerden dolayı olabilir. Ama yoğun gübreleme yapıldığından $\mathrm{Cd}$ birikiminin fosfatlı gübreden kaynaklanabileceği de söylenebilir. Bu alanlarda $\mathrm{Fe}$ eksikliğinin bitkilerde gözle görülebilir olması ve bu eksikliğin ağır metallerin fazlalığından kaynaklanabileceği gözardı edilmemelidir. Çalışma alanından alınan topraklarda alınabilir $\mathrm{Fe}$ analizlerinde toprakların demir içeriklerinin $\% 92,7$ 'si az; $\% 3,7$ 'sı orta; 3,6'sı yüksek bulunmuştur.

Çalışmanın Önemi ve Etkisi: Elde edilen sonuçlar bu metallerin yapılacak araştırmalarla bitkilere, hayvanlara ve insanlara gıda zinciriyle geçişi dikkatlice izlenmesi gıda güvenliği açısından önemli olup olmadığı uygun ekstraktörlerle analiz edilip söz konusu ekstraktörün koreleasyon kalibrasyon çalışmaları ile seçilmesi sonucu elde edilen veriler, limit değerlerle karşılaştırılıp toksik olup olmayacağı farklı bir araştırma ile netleştirilmesi gerekmektedir. Bu çalışma durum çalışması olup, söz konusu kayaçların olası ağır metal potansiyelini ortaya koyan bir araştırmadır. Ancak çözünerek bitkiye geçişi veya diğer elementlerin alımına antagonistik etki yapıp yapmayacağı, çeşitli kileyt çözücülerle ekstrakte edilebilir dozunun belirlenmesinin araştırılması ile mümkün olabilecektir.

Anahtar kelimeler: Potansiyel toksik ağır metaller, gıda güvenliği, ağır metal, kirlilik.

\section{TEŞEKKÜR}

Bu çalışma, Antepfıstığı Araştırma Enstitüsü Müdürlüğü tarafından TAGEM/TSKAD/13/A13/PO7/01-10 no'lu proje kapsamında yürütülen projenin verileri kullanılarak hazırlanmıştır.

\section{ÇIKAR ÇATIŞMASI BEYANI}

Makale yazarları aralarında herhangi bir çıkar çatışması olmadığını beyan ederler.

\section{ARAŞTIRMACILARIN KATKI ORANI BEYAN ÖZETI}

Yazarlar makaleye eşit oranda katkı sağlamış olduklarını beyan ederler. 


\section{KAYNAKLAR}

Anonim (2010) "27605 sayılı 08.06.2010 tarihli Toprak Kirliliği Kontrolü ve Noktasal Kaynaklı Kirlenmiş Sahalara Dair Yönetmelik (TKKY 2010/27605).

Bolat I, Kara Ö (2017) Bitki besin elementleri: Kaynakları, işlevleri, eksik ve fazlalıkları. Bartın Orman Fakültesi Dergisi 19(1): 218-228.

Buczyńska A, Tarkowski S (2005) Environmental exposure and birth outcomes. International Journal of Occupational Medicine and Environmental Health 18(3): 225-232.

Gönül i, Delikanlı A, Serin S (2019) Yüksek pH Dayanımlı Yeni Tip Demir Şelat Formülünün Hazırlanması ve Yerfıstığı Üzerine Etkilerinin İncelenmesi. Çukurova Üniversitesi Mühendislik-Mimarlık Fakültesi Dergisi 34(3): 261-270.

Jackson M L (1958) Soil chemical analysis prentice Hall. Inc., Englewood Cliffs, NJ, 498: 183-204.

Khan NI, Owens G, Bruce D, Naidu R (2009). Human arsenic exposure and risk assessment at the landscape level: a review. Environmental Geochemistry and Health 31: 143-166. doi: 10.1007/s10653-008-9240-3 PMID: 19172401.

Khan MR, Khan MM (2010) Effect of varying concentration of nickel and cobalt on the plant growth and yield of chickpea. Aust. J. Basic Appl. Sci. 4(6): 1036-1046.

Kırpık M, Büyük G, İnan M, Çelik A (2017) The heavy metal content of some herbal plants on the roadside of Adana-Gaziantep highway. Gaziosmanpașa Üniversitesi Ziraat Fakültesi Dergisi 34(1): 129-136.

Kullu B, Patra D K, Acharya S, Pradhan C, Patra HK (2020) AM fungi mediated bio accumulation of hexavalent chromium in Brachiaria mutica-a mycorrhizal phytoremediationapproach. Chemosphere 258: 127337.

Lavkor I, Çelik i (2006) Osmaniye illi ve çevresinde bulunan farklı ana materyaller üzerinde oluşan topraklarda, toprak verimliliği-bitki besleme ilişkilerinin belirlenmesi. Çukurova Üniversitesi Fen Bilimleri Enstitüsü Toprak Ana Bilim Dalı Yüksek Lisans Tezi. Adana, 44-51.

Lešková A, Giehl RF, Hartmann A, Fargašová A, von Wirén $N$ (2017) Heavy metals induce iron deficiency responses at different hierarchic and regulatory levels. Plant Physiology 174(3): 1648-1668.

Li Z, Li L, Chen GPJ (2005) Bioavailability of Cd in a soilrice system in China: soil type versus genotype effects. Plant and Soil 271: 165-173.
Lindsay WL, Norwell WA (1978) Development of a DTPA soil test for zinc, iron, manganese, and copper. Soil Science Society America Journal 42: 421-428

Lu Y, Yin W, Huang LB, Zhang GL, Zhao YG (2011) Assessment of bioaccessibility and exposure risk of arsenic and lead in urban soils of Guangzhou City, China. Environmental Geochemistry and Health 33: 93-102. doi: 10.1007/s10653-010-9324-8 PMID: 20524051.

Nakonieczny M (2007 Structural and functional adaptations of Chrysolina pardalina (Chrysomelidae; Coleoptera) to development on nickel hyperaccumulator Berkheya coddii (Asteraceae) - a comparative study with Chrysolinaher bacea. Silesia: University of Silesia Press.

Naser HM, Sultana S, Mahmud NU, Gomes R, Noor S (2012) Heavy metal levels in vegetables with growth stage and plant species variations. Bangladesh $\mathrm{J}$. Agric. Res. 36(4): 563-574.

Oze C, Skinner C, Schroth A, Coleman RG (2008) Growing up green on serpentine soils: biogeochemistry of serpentine vegetation in the Central Coast Range of California. Appl. Geochem. 23: 3391-3403.

Pandey J, Pandey U (2009) Accumulation of heavy metals in dietary vegetables and cultivated soil horizon in organic farming system in relation to atmospheric deposition in a seasonally dry tropical region of India. Environmental Monitoring and Assessment 148(1-4): 61-74.

Rascio N, Navari-Izzo F (2011). Heavy metal hyperaccumulating plants: how and why do they do it? And what makes them so interesting? Plant Science 180(2): 169-181.

Salmanzadeh M, Balks MR, Hartland A, Schipper LA (2016) Cadmium accumulation in three contrasting New Zealand soils with the same phosphate fertilizer history. Geoderma Regional 7(3): 271-278.

Seven T, Can B, Darende BN, Ocak S (2018) Hava ve toprakta ağır metal kirliliği. Ulusal Çevre Bilimleri Araştırma Dergisi 1(2): 91-103.

TAGEM (2018) Türkiye Tarım Topraklarının Bitki Besin Maddesi ve Potansiyel Toksik Element Kapsamlarının Belirlenmesi, Veri Tabanının Oluşturulması ve HaritalanmasI. TAGEM/TSKAD/13/A13/PO7/01-10.

Tang L, Yasir H, Afsheen Z, Zulfiqar AS, He ZL, Bilal H, Hanumanth KG, Yang XE (2019) Characterization of fava bean (Vicia faba L.) genotypes for phytoremediation of cadmium and lead cocontaminated soils coupled with agro-production. Ecotoxicol Environmental Safety 171: 190-198.

Tót G, Hermann T, Da Silva MR, Montanarella L (2016) Heavy metals in agricultural soils of the European 
Union with implications for food safety. Environment International 88: 299-309.

Xu Y, Dai S, Meng K, Wang Y, Ren W, Zhao L, Teng Y (2018). Occurrence and risk assessment of potentially toxic elements and typical organic pollutants in contaminated rural soils. Science of the Total Environment 630: 618-629.

Zhang XY, Lin FF, Wong MT, Feng XL, Wang K (2009) Identification of soil heavy metal sources from anthropogenic activities and pollution assessment of Fuyang County, China. Environ. Monit. Assess. 154: 439-449. doi: 10.1007/s10661-008-0410-7 PMID: 18597177.
Zhu YG, Sun GX, Lei M, Teng M, Liu YX, Chen NC, Wang LH, Carey AM, Deacon C, Raab A, Meharg A, Wiiliams PN (2008) High percentage inorganic arsenic content of mining impacted and nonimpacted Chinese rice. Environmental Science \& Technology 42: 5008-5013. 